\title{
Age differences in visual-spatial memory performance: Do children really out-perform adults when playing Concentration?
}

\author{
LYNNE BAKER-WARD \\ North Carolina State University, Raleigh, North Carolina \\ and \\ PETER A. ORNSTEIN \\ University of North Carolina at Chapel Hill, Chapel Hill, North Carolina
}

\begin{abstract}
Twenty-six adults and 123 children (ages 5 to 9 ) played individually a modified version of Concentration. Each player examined two uncovered pictures on each of a series of trials until 16 matching pairs were found. There were no age differences in the number of trials required to locate all matches. On a measure that reflects "perfect" task performance, however, children performed significantly better than adults. The sample's typicality with regard to verbal memory was evidenced by performance on a digit span task. These findings support the long-held belief that visual-spatial memory performance actually declines in development.
\end{abstract}

Among laymen and psychologists alike, accounts of children's memory capabilities often reflect the view that there is an age-related decline in visual-spatial memory performance. Anecdotal reports (e.g., Crovitz, 1970, p. 42) hold that children win in competition with adults in Concentration and similar games that require memory for pictures and their locations. Developmental theorists of radically different orientations (Bruner, 1964; Kendler \& Kendler, 1962; Piaget \& Inhelder, 1969; Preyer, 1893) have long postulated a transition from earlier visual to later symbolic modes of representation. This transition may involve the loss of some capacity for visual-spatial memory (see Luria, 1968).

Data to support this transition, however, are limited to demonstrations of the younger child's sensitivity to the visual characteristics of displays (Bruner \& Kenney, 1966) and the absence of age-related differences in performance in the early stages of visual information processing (Morrison, Holmes, \& Haith, 1974). Furthermore, findings of encoding flexibility in children as well as in adults (Tversky, 1969, 1973) and the documentation of agerelated increases in spatial memory performance (Mandler, Seegmiller, \& Day, 1977) are inconsistent with a developmental decline in visual-spatial memory perfor-

This work was supported in part by Grant HD 08459 from the United States Public Health Service. We thank Herbert Crovitz, Robert Guttentag, Marcy Lansman, Nancy Myers, David Rosenbaum, David Rubin, Jaan Valsiner, and Thomas Wallsten for their helpful comments on earlier drafts of this manuscript. The assistance of Elizabeth Levy, Ralph Wenger, and Margaret Ann Smith is also gratefully acknowledged. Portions of this paper were reported at the annual meetings of the American Psychological Association, Anaheim, CA, August 1983. Requests for reprints should be sent to Lynne Baker-Ward, Department of Psychology, North Carolina State University, Raleigh, NC 27695-7801. mance. Given (1) the presumed importance of developmental changes in visual memory, (2) the persistence of anecdotal accounts of such changes, and (3) the paucity of consistent data, we undertook a reexamination of the issue.

\section{METHOD}

Subjects

Forty-two kindergartners, 43 second graders, and 38 fourth graders, with mean ages of $6.0,7.9$, and 9.9 years, respectively, were recruited from public schools. The adult sample comprised 26 college students with a mean age of 20.2 years. There were approximately equal numbers of males and females at each grade level, including college.

\section{Apparatus and Stimuli}

A modified version of the commercial board game Concentration was used in this research. The game was a $50 \times 28 \mathrm{~cm}$ rectangle containing 32 apertures. Under each opening was positioned a member of one of 16 matching pairs of pictures of the Sesame Street Muppet characters. Two game boards, differing only in the random positioning of the pictures, were used, and approximately half of the subjects at each age level worked with each board.

\section{Procedure}

The subjects were individually instructed to play Concentration without a partner. On each trial, the subject lifted two checkers, thus revealing two pictures. If the pictures matched, the checkers were removed from the board; if not, the checkers were replaced. This procedure continued until the subject found all 16 matches. Each subject also completed a standard digit span task. The order of presentation of the tasks was counterbalanced across subjects.

\section{RESULTS}

The data were pooled across sex of subject, game board, and task order after preliminary analyses revealed no effects of these variables. 
There was no effect of grade level on the number of trials required to clear the board. The kindergartners required an average of 45.2 trials $(S D=8.6)$; the second graders, $43.3(S D=8.3)$; the fourth graders, 41.5 $(S D=6.5)$; and the adults, $43.8(S D=7.9)$. However, grade differences were found when a measure that eliminated lucky guesses and matches made after errors in performance was considered. A "perfect"' was scored when a match was made as soon as the subject knew the locations of both members of the matching pair. The kindergarten children scored 8.2 perfects $(S D=2.4)$; the second graders, $8.1 \quad(S D=2.6)$; the fourth graders, 8.3 $(S D=2.4)$; and the adults, only $6.5(S D=2.4)[F(3,141)$ $=3.59, p<.01]$. There were no differences among the groups of children.

As expected, an age-related increase in digit span was observed. The kindergartners repeated 4.7 digits $(S D=0.9)$; the second graders, $5.4(S D=1.2)$; the fourth graders, $5.5(S D=1.1)$; and the adults, $6.9(S D=0.9)$ $[F(3,14)=23.10, p<.01]$.

\section{DISCUSSION}

These results provide evidence for children's superior visual-spatial memory performance. In contrast to most measures of problem solving (e.g., Ghoulson, Levine, \& Phillips, 1972), the adults were not superior to the children in the number of trials that were required to complete the board game. Furthermore, the children actually outperformed the adults on a measure reflecting the number of perfect matches. It seems likely that the trials-to-finish measure is more reflective of global game strategies than is the number-of-perfect-matches measure. If so, the equivalent performance of the subjects, in terms of the numbers of trials required to empty the board, is all the more remarkable, because it was obtained in spite of the known increases with age in the application of mnemonic strategies (see Ornstein, 1978). Furthermore, analysis of the perfect matches suggests that the children were superior on this more finely grained index of visual memory performance, a difference that may in fact be underestimated to the extent to which the measure does not exclude strategic factors completely.

Could the present findings stem from some aspect of the task other than its visual-spatial memory component? Although the procedure involved the use of a modified children's game, the college-aged subjects, like the children, demonstrated a serious approach to the task. A similar concern involves the possibility that the stimuli used in the visual memory task were more familiar to the children than to the adults. If so, the children's apparent superiority relative to adult performance may be attributed to knowledge-base effects (see Chi, 1978). However, there is no evidence to suggest that the stimuli were more familiar to the children than to the adults. The adults reported continued exposure to Sesame Street's Muppet characters through various popular media presentations, and spontaneously identified many of the characters while performing the task. It should be noted in this regard that the anecdotal reports of children's prowess in games of Concentration involved stimuli such as playing cards that could be expected to be much less familiar to children than to their parents (e.g., see Crovitz, 1970). The results thus provide evidence that is consistent with the assertion that in some aspects of visual-spatial memory performance, children are superior to adults. However, it must be emphasized that the present findings do not necessarily support the hypothesis that the acquisition of verbal mediation in development substantially diminishes the capacity for the visual mode of representation. In light of data that argue for flexibility across age in encoding modality (Tversky, 1973), it is possible that the present findings result from age-related changes in preference for verbal as opposed to visual encoding, and not a decline in visual skill per se. Furthermore, the absence of differences in performance between kindergartners and fourth graders suggest that the achievement of operational thought, which is assumed to involve a change in the preferred mode of encoding, does not necessarily imply a decline in visual memory performance. Nonetheless, the present data do provide initial verification of a set of beliefs long held and articulated, but never fully supported. Perhaps Concentration is really a child's game.

\section{REFERENCES}

Bruner, J. S. (1964). The course of cognitive growth. American Psychologist, 19, 1-15.

Bruner, J. S., \& KenNeY, H. (1966). On multiple ordering. In J. S. Bruner, R. R. Olver, \& P. M. Greenfield (Eds.), Studies in cognitive growth (pp. 154-167). New York: Wiley.

CHI, M. T. H. (1978). Knowledge structures and memory development. In R. S. Siegler (Ed.), Children's thinking: What develops? (pp. 7396). Hillsdale, NJ: Erlbaum.

Crovitz, H. (1970). Galton's walk. New York: Harper \& Row.

Ghoulson, B., Levine, M., \& Philuips, S. (1972). Hypotheses, strategies, and stereotypes in discrimination learning. Journal of Experimental Child Psychology, 13, 423-446.

Kendler, H. H., \& Kendler, T. S. (1962). Vertical and horizontal processes in problem solving. Psychological Review, 69, 1-16.

LURIA, A. R. (1968). The mind of a mnemonist. New York: Basic Books.

Mandler, J. M., Seegmiller, D., \& Day, J. (1977). On the coding of spatial information. Memory \& Cognition, 5, 10-16.

Morrison, F. J., Holmes, D. L., \& HAITH, M. M. (1974). A developmental study of the effect of familiarity on short-term memory. Journal of Experimental Child Psychology, 18, 412-425.

ORNSTEIN, P. A. (Ed.). (1978). Memory development in children. Hillsdale, NJ: Erlbaum.

Piaget, J., \& Inhelder, B. (1969). The psychology of the child. New York: Basic Books.

PreYer, W. (1893). The mind of the child. (Vol. 1). New York: Appleton.

TVERSKY, B. G. (1969). Pictorial and verbal encoding in a short-term memory task. Perception \& Psychophysics, 6, 225-233.

TVersKy, B. G. (1973). Pictorial and verbal encoding in preschool children. Developmental Psychology, 8, 149-153.

(Manuscript received for publication November 2, 1987.) 